\title{
International research sheds light on waiting times
}

About half of the countries in the Organization for Economic Cooperation and Development $\infty$ including Canada - report having problems with waiting times for elective surgery, reports the OECD. A study by OECD staff members Jeremy Hurst and Luigi Siciliani examines the causes of variations in wait times across countries and determines which

Median inpatient waiting times in $\mathbf{2 0 0 0}$ for selected procedures, by number of days

\begin{tabular}{lcccc}
\hline Country & $\begin{array}{c}\text { Hip } \\
\text { replacement }\end{array}$ & $\begin{array}{c}\text { Knee } \\
\text { replacement }\end{array}$ & $\begin{array}{c}\text { Cataract } \\
\text { surgery }\end{array}$ & CABG \\
\hline Australia & 98 & 120 & 120 & 22 \\
Canada & $112(\mathrm{BC})$ & $136(\mathrm{BC})$ & $80(\mathrm{BC})$ & $23(\mathrm{ON})$ \\
& $105(\mathrm{MN})$ & $105(\mathrm{MN})$ & & $10(\mathrm{SK})$ \\
& $162(\mathrm{SK})$ & $291(\mathrm{SK})$ & & \\
Denmark & 87 & 90 & 36 & 34 \\
Finland & 148 & 202 & 189 & 25 \\
Norway & 99 & 132 & 28 & 191 \\
England & 211 & 261 & 182 & \\
\hline
\end{tabular}

Note: $\mathrm{CABG}=$ coronary artery bypass grafting, $\mathrm{NA}=$ not available.

Source: Siciliani L, Hurst J. Explaining waiting times variations for elective surgery across OECD countries. OECD Health Working Paper 2003;7:1-72.

policies are most effective in addressing excessive waiting times.

Among the countries experiencing waiting time problems, the availability of doctors was the most significant factor. An increase of 0.1 practising physicians per 1000 population was linked to a reduction of median waiting times of 7.6 days across all procedures included in the study. Simi-

Health Policy larly, an increase of 0.1 specialists per 1000 population was associated with a reduction of 8.9 days in median waiting times.

The level of health expenditures was also found to be a significant explanatory factor, with each increase in total health expenditure per capita of $\$ 100$ associated with a reduction of median waiting times of 6.1 days.

In the comparison between countries with and without waiting times, the authors found that low supply of acute care beds was a significant factor in explaining the presence of waiting times. They also found fee-for-service remuneration for specialists to be negatively associated with the presence of waiting times, and suggested that activity-based funding for hospitals (payment on the basis of services provided and case mix, rather than global funding) may also help reduce waiting times. - Marcel Saulnier, Director, Policy Research, CMA

\section{Saskatchewan's new system tracks surgical waits}

While other provinces juggle waiting lists and frustrated patients, Saskatchewan is implementing the country's first comprehensive system to rate and track all patients waiting for surgery. Target waiting times have also been set.

Established 2 years ago, the Saskatchewan Surgical Care Network will complete its province-wide list, which includes the name of the surgeon, the hospital, the type of surgery and how long the patient has been waiting, by the end of May.

No matter where patients \& live or who their surgeon is, under the new system patients will be rated on a common scale between 1 and 6 depending on how quickly they should receive surgery. "We no longer talk $\because \ddot{\circ}$ about emergency. That's prior$\AA$ ity 1 ," says Peter Glynn, chair of the network. Priority 1 patients receive surgery within 24 hours. Priority 2, urgent cases, should receive surgery within 3 weeks. Those with the lowest elective rating, priority 6 , should receive surgery within 12 months.

The government says the new system is more equitable and will reduce waiting times.

Initially, the network is concentrating on 2 patient categories: those waiting for cancer surgery and those who have been waiting the longest overall. The goal is to complete $95 \%$ of cancer surgeries within 3 weeks, and to complete all surgeries for patients who have been waiting longer than 18 months.

Last year, a Fraser Institute survey indicated that Saskatchewan had the longest average waiting time for surgery in the country, at close to 30 weeks.
"There are people who have been waiting much too long [for surgery]," says Glynn. "We are expecting the regional health authorities to become much more responsible for access to surgical care and to use this information to monitor performance."

The wait for surgery can vary depending on the surgeon and the location. Now information about waiting times in each location is posted at www.sasksurgery .ca, so physicians can choose where to refer their patients. "Physicians have been pleading for this information," says Glynn.

He says Saskatchewan's network operates much like similar projects in other provinces, including the cataract initiative in Manitoba. In March, Saskatchewan allocated \$2.5 million to the initiative. - Amy fo Ebman, Saskatoon 